\title{
ANALISIS PELAKSANAAN PENGELOLAAN DANABANTUAN OPERASIONAL SEKOLAH (BOS) PADA SEKOLAH DASAR NEGERI 34/1 TERATAI
}

\author{
Niki Kosasih
}

STIE Graha Karya Muara Bulian, Jambi, Indonesia

\begin{abstract}
The purpose of this study was to determine the implementation of the management of the school operational assistance fund (BOS). This research was conducted at SDN 34./1 Teratai. The method used in this research is descriptive qualitative research method. Where the focus of this research is to describe / describe the Implementation of BOS SD Fund Management in 34 / I Teratai Public Elementary School, Muara Bulian Subdistrict, Batang Hari Regency, 2017. Data collection was carried out by observation, interviews and documentation. Based on the analysis carried out, it can be concluded that the implementation of the management of BOS funds at SDN 34 / I Teratai has been running as it should in accordance with the Responsibility instructions for the use of BOS funds in 2017 even though the management of BOS funds has been carried out as well as possible but errors and shortcomings are still found even though only a small scope such as misplaced position and tax issues and even then it does not happen again but it is not an intentional element of the BOS funds manager and the problems encountered can still be corrected and resolved properly.
\end{abstract}

Keywords: Implementation, Management, School Operational Assistance Fund (BOS)

\section{PENDAHULUAN}

Pendidikan merupakan bagian penting dari proses pembangunan nasional yang ikut menentukan pertumbuhan ekonomi suatu negara. Pendidikan juga merupakan investasi dalam pengembangan sumber daya manusia, dimana peningkatan kecakapan dan kemampuan diyakini sebagai faktor pendukung upaya manusia dalam mengarungi kehidupan yang penuh dengan ketidakpastian.

Bangsa yang maju adalah bangsa yang peduli akan pendidikan dan dapat tergambarkan dari pencapaian pendidikan warga negaranya. Pencapaian pendidikan suatu bangsa dapat dilihat dari kesesuaian antara tujuan dan keterlaksanaan pendidikan. Pendidikan diperlukan dan dipandang sebagai kebutuhan dasar bagi masyarakat yang ingin maju. Demikian halnya bagi masyarakat Indonesia yang memiliki wilayah yang sangat luas.

Dalam Undang-Undang Dasar Republik Indonesia Tahun 1945 pasal 31 ayat (1) menyebutkan bahwa setiap warga negara berhak mendapat pendidikan, dan ayat (3) menegaskan bahwa pemerintah mengusahakan dan menyelenggarakan satu sistem pendidikan nasional yang meningkatkan keimanan dan ketakwaan serta akhlak mulia dalam rangka mencerdaskan kehidupan bangsa yang diatur dengan undang-undang. Untuk itu, seluruh komponen bangsa wajib mencerdaskan kehidupan bangsa yang merupakan salah satu tujuan negara Indonesia.

Tujuan pendidikan secara umum adalah individu yang berkarakter atau bermoral, yaitu individu yang memiliki kebebasan, kesempurnaan, kemauan baik, kebenaran dan kesamaan. Menurut pasal 3 Undang - undang Nomor 20 Tahun 2003, tujuan pendidikan nasional adalah untuk mengembangkan potensi peserta didik agar menjadi manusia yang beriman dan bertaqwa kepada Tuhan Yang Maha Esa, berakhlak mulia, sehat, berilmu, cakap, kreatif, mandiri dan menjadi warga negara yang demokratis serta bertanggungjawab. Adapun fungsi nasional pendidikan adalah mengembangkan kemampuan dan membentuk watak serta peradaban bangsa yang bermatabat dalam rangka mencerdaskan kehidupan bangsa. 
Sebagai upaya untuk melaksanakan kewajiban menyelenggarakan pendidikan dasar tanpa biaya, pemerintah menciptakan program Bantuan Operasional Sekolah (BOS). Pada awalnya BOS ini adalah bentuk kompensasi kenaikan bahan bakar minyak pada tahun 2005 tepatnya pada bulan juli bersamaan dengan tahun ajaran baru, dengan tujuan awal adalah untuk mempercepat pencapaian program Wajib Belajar (Wajar) 9 tahun. Tahun 2015 program Wajib Belajar (Wajar) menjadi 12 tahun

Mulai tahun 2009 pemerintah telah melakukan perubahan tujuan, pendekatan dan orientasi program BOS, dari perluasan akses menuju peningkatan kualitas. Program BOS untuk selanjutnya bukan hanya berperan untuk mempertahankan jumlah peserta didik saja, namun juga harus berkontribusi dalam peningkatan mutu pendidikan dasar. Dalam perkembangannya, program BOS mengalami peningkatan biaya satuan pada tahun 2012 s/d 2014 jumlahnya Rp. 580.000 / Siswa/Tahun menjadi Rp. 800.000/siswa/Tahun pada tahun 2015 hingga sekarang hal itu didasari oleh peningkatan alokasi anggaran Pendidikan yang tertuang dalam Peraturan Menteri Keuangan sesuai dengan RAPBN selain itu juga terjadi perubahan mekanisme penyaluran. Sejak tahun 2012 penyaluran dana BOS dilakukan dengan mekanisme transfer ke provinsi yang selanjutnya ditransfer ke rekening sekolah secara langsung dalam bentuk hibah. Oleh karena itu, kenaikan jumlah dana BOS diharapkan dapat menjadi pilar utama mewujudkan pendidikan dasar tanpa dipungut biaya.

Secara umum program BOS bertujuan untuk meringankan beban masyarakat terhadap pembiayaan pendidikan dalam rangka wajib belajar 12 tahun yang bermutu, serta berperan dalam mempercepat pencapaian Standar Pelayanan Minimal (SPM) pada satuan pendidikan-satuan pendidikan yang belum memenuhi SPM, dan pencapaian Standar Nasional Pendidikan (SNP) pada satuan pendidikan-satuan pendidikan yang sudah memenuhi SPM. Secara khusus program BOS bertujuan untuk membebaskan pungutan bagi seluruh peserta didik SD negeri terhadap biaya operasi satuan pendidikan.

Menurut ketentuan, dana BOS diterima oleh sekolah secara utuh, dan dikelola secara mandiri oleh sekolah dengan melibatkan dewan guru dan Komite Sekolah dengan menerapkan MBS diantaranya sekolah mengelola dana secara profesional dengan menerapkan prinsip efisien, efektif, akuntabel. Sekolah boleh menggunakan dana BOS tersebut untuk beberapa jenis pengeluaran sesuai juklak program dan berdasarkan Rencana Kegiatan dan Anggaran Sekolah (RKAS) yang disusun oleh sekolah dan Komite Sekolah.

Semua unsur yang terlibat dalam pengelolaan BOS ini diharapkan dapat memahami ketentuan-ketentuan teknis yang harus dijalankan dalam rangka penyelenggaraan program BOS. Karena, kesalahpemahaman oleh pengelola dapat menimbulkan hambatan dalam pelaksanaan program BOS.

\section{METODE PENELITIAN Jenis Penelitian}

Penelitian merupakan cara ilmiah untuk mendapatkan data dengan tujuan dan kegunaan tertentu ( Sugiyono, $2016: 3$ ). Dalam penelitian ini jenis penelitian yang digunakan adalah penelitian berbentuk deskriptif kualitatif. Fokus penelitian ini adalah menggambarkan/mendeskripsikan Pelaksanaan Pengelolan Dana BOS SD di SD Negeri 34/1 Teratai, Kecamatan Muara Bulian Kabupaten Batang Hari Tahun 2017.

\section{Jenis Data dan Sumber Data}

Adapun jenis dan sumber data yang penulis gunakan dalam penelitian ini adalah:

1) Data Primer

Data Primer adalah data yang diperoleh penulis melalui observasi atau 
pengamatan langsung dari sumber asli yaitu di SD Negeri 34/1 Teratai, Kecamatan Muara Bulian Kabupaten Batang Hari. Data dikumpulkan untuk menjawab pertanyaan penelitian yang sesuai dengan keinginan peneliti. Data diperoleh setelah melakukan penelitian dari responden yang berkaitan dengan masalah dan tujuan penelitian.

2) Data Sekunder

Data Sekunder adalah data yang diperoleh secara tidak langsung oleh peneliti, peneliti memperolehnya dari upaya - upaya pengumpulan . Data jenis ini dapat diperoleh penulis dari dokumen - dokumen dan buku - buku literature yang memberikan informasi tentang masalah yang menyangkut penelitian. Data sekunder umumnya berupa bukti, catatan atau laporan historis yang telah tersusun dalam arsip.

\section{Metode Pengumpulan Data}

Untuk memperoleh data yang otentik yang mengarah pada kebenaran, maka penulis menggunakan teknik pengumpulan data sebagai berikut :

1. Field Research (studi lapangan) adalah sumber data yang diperoleh dengan mendatangi tempat atau objek yang diteliti secara langsung dengan cara :

a. Observasi yaitu pengumpulan data dengan cara melakukan pengamatan langsung. Dalam penelitian ini observasi dilakukan untuk mengetahui keadaan umum SD Negeri 34/1 Teratai. Pada khususnya observasi dilakukan untuk mengamati hasil Pengelolaan Dana BOS SD Negeri 34/1 Teratai.

b. Wawancara/Interview, merupakan tanya jawab yang dilakukan dengan pihak-pihak yang terkait langsung dengan penelitian ini. Wawancara dilakukan kepada Kepala Sekolah, Komite Sekolah, Bendahara BOS, dan Guru. Wawancara dilakukan untuk mengetahui secara riil Pengelolaan Dana BOS di SD Negeri
34/1 Teratai Kecamatan Muara

Bulian Kabupaten Batang Hari.

2. Library Research (studi kepustakaan) adalah salah suatu metode pengumpulan data dengan mencari dan mengumpulkan data - data atau informasi yang berhubungan dengan masalah yang di teliti dengan mempelajari literatur dan sumber lain yang telah ada sebelumnya dengan mempelajari buku-buku referensi, laporan-laporan, majalahmajalah, jurnal-jurnal dan media lainnya yang berkaitan dengan obyek penelitian.

\section{Alat Analisis Data}

Alat analisa yang digunakan dalam penelitian ini adalah analisa kualitatif yaitu analisis data dan fakta yang tidak menggunakan model matematik atau statistik dan proses penelitian dimulai dengan menyusun asumsi dasar dan berfikir yang akan digunakan dalam penelitian.

Jenis penelitian kualitatif yang menjadi instrumen atau alat penelitian adalah peneliti itu sendiri. Data penelitian kualitatif masih belum diketahui, sumber data belum teridentifikasi secara jelas/pasti, dan cara-cara menggali data belum diketahui, baik dalam mengeksplorasi maupun mengungkapkan data sehingga keberadaan alat pengumpul data sangat dibutuhkan (Djunaidi Ghony \& Fauzan Almanshur, 2012 : 96).

\section{HASIL DAN PEMBAHASAN \\ Tahapan Pelaksanaan Dana BOS Pada SDN 34/1 Teratai}

Dalam pelaksanaan dana BOS pada SDN 34/1 Teratai telah sesuai dengan Petunjuk Teknis Penggunaan dan Pertanggungjawaban Keuangan Dana Bantuan Operasional Sekolah. Dimana pelaksanaan dana BOS sekolah dilakukan dengan tahap-tahapan sebagai berikut :

\section{Penyusunan RKAS}

Pelaksanaan dana BOS sekolah dilakukan dengan terlebih dahulu menyusun Rencana Kegiatan dan Anggaran Sekolah (RKAS) sebelum menerima dan BOS. RKAS mencakup 
seluruh kegiatan sekolah yang akan dilaksanakan selama satu tahun.

\section{Pengambilan Dana}

Pengambilan dana BOS dilakukan oleh bendahara sekolah/bendahara BOS atas persetujuan kepala sekolah dan dapat dilakukan sewaktu-waktu sesuai kebutuhan sekolah

\section{Penggunaan Dana}

Setelah sekolah menerima dana BOS maka sekolah harus merealisasikan dana sesuai RKAS yang telah disusun. Pelaksanaan kegiatan disekolah terkadang mengalami ketidaksesuaian saat dijalankan dengan rencana yang telah dianggarkan di awal tahun pelajaran pada penyusunan RKAS. Ketidaksesuaian rencana yang telah disusun oleh sekolah, akibat adanya keadaan yang nyatanya berbeda dengan anggaran yang telah dibuat sekolah. Sehingga sekolah harus membuat kegiatan perubahan untuk menggantikan kegiatan yang tidak terealisasi.

\section{Pembukuan}

Pembukuan dana BOS dilakukan oleh bendahara dana BOS. Pembukuan tersebut berisi jumlah dana yang dikeluarkan serta rincian pengeluaran. Pembukuan tersebut terdiri dari buku kas umum, buku pembantu kas,buku pembantu bank dan buku pembantu pajak. Pembukuan dilakukan rutin setiap bulan oleh bendahara BOS dengan menyertakan bukti transaksi terhadap dana yang dikeluarkan berupa nota dan kwitansi bermaterai sesuai jumlah belanja. Bukti fisik tersebut berguna sebagai bukti fisik atas transaksi penggunaan dana BOS, sebagai pertanggung jawaban pengelola BOS sekolah terhadap pemerintah yang dilaporkan dalam bentuk SPJ setiap bulannya.

\section{Perpajakan}

Untuk kewajiban perpajakan SDN 34/1 Teratai telah melakukan pembayaran pajak melalui bank daerah yaitu bank 9 jambi terkait transaksi-transaksi yang telak dilaksanakan. Penyetoran pajak dilaksanakan berdasarkan petunjuk teknis BOS dan peraturan UndangUndang yang berlaku. Pajak yang dikeluarkan adalah pajak pengeluaran penggunaan dana BOS dengan nominal mulai dari Rp. 1.000.000.- dan lebih dari Rp. 1.000.000.- .

\section{Pelaporan}

Pelaporan pertanggung jawaban penggunaan dana BOS dilakukan sekolah dengan mengirimkan laporan kepada Dinas Kabupaten kota dalam bentuk SPJ pembelanjaan yang telah disusun sesuai ketentuan. Laporan dana BOS juga dilakukan secara online melalui website resmi kemdikbud. Selain mengirimkan laporan kepada dinas terkait sekolah juga mempublikasikan penggunaan dana BOS dengan cara menempelkan rincian penggunaan dana BOS di sebuah papan pengumuman khusus dana BOS, serta penyampaian langsung dalam rapat bersama wali murid,guru dan komite. Dengan begitu semua mengetahui kemana dana tersebut digunakan.

\section{Pengelolaan Dana BOS Pada SDN 34/1 Teratai}

Dalam pengelolaan dana BOS terdapat ketentuan - ketentuan yang telah diatur didalam petunjuk teknis penggunaan dan pertanggungjawaban keuangan dana BOS yang diterbitkan oleh Direktorat Jendral Pendidikan Dasar dan Menengah Dinas Pendidikan dan Kebudayaan Republik Indonesia. Yaitu tentang penggunaan dana bos yang telah diatur sesuai dengan komponen pembelanjaan. SDN 34/1 Teratai menggunakan dana sesuai dengan ketentuan yang telah ditetapkan.

Setelah dana BOS diterima sekolah. Tim manajemen BOS sekolah membelanjakan dana sesuai RKAS yang telah disusun. Setiap transaksi dilengkapi dengan nota dan kwitansi bermaterai berdasarkan ketentuan sesuai dengan jumlah transaksi. Sebelumnya semua kegiatan sekolah telah direncanakan secara 
menyeluruh dan terdapat rincian anggaran yang telah direncanakan.

Pengelolaan dana BOS dilakukan sesuai asas yang berlaku yaitu secara transparan dan terbuka. Realisasi penggunaan dana untuk masing-masing anggaran disesuaikan dengan peraturan sesuai komponen menurut juknis BOS. Rincian realisasi penggunaan dana lebih jelas akan dijelas kan dalam tabel berikut:

Tabel 1. Realisasi dana BOS SDN 34/1 Teratai Tahun 2017

\begin{tabular}{clrr}
\hline No & \multicolumn{1}{c}{ Komponen Pembiayaan } & $\begin{array}{c}\text { Jumlah } \\
\text { Dana (Rp) }\end{array}$ & $\begin{array}{c}\text { Persentase } \\
\text { Penggunaan }(\%)\end{array}$ \\
\hline 1. & Pengembangan Perpustakaan & 56.184 .000 & 20,54 \\
2. & Kegiatan Penerimaan Peserta Didik Baru & 6.527 .150 & 2,39 \\
3. & Kegiatan Pembelajaran dan Ekstrakurikuler & 68.047 .750 & 24,87 \\
4. & Kegiatan Evaluasi Pembelajaran & 17.239 .500 & 6,30 \\
5. & Pengelolaan Sekolah & 27.200 .000 & 9,94 \\
6. & Pengembangan Profesi Guru dan Tenaga Kependidikan serta & 17.660 .000 & 6,45 \\
7. & Pengembangan Manajemen Sekolah & 14.807 .600 & 5,41 \\
8. & Pemgananan Daya dan Jasa & 27.439 .000 & 10,03 \\
9. & Pembayaran Honor & 32.995 .000 & 12,06 \\
10. & Pembelian/ Perawatan Alat Multimedia Pembelajaran & 5.500 .000 & 2,01 \\
11. & Lainnya & 0 & 0,00 \\
& $\quad$ Jumlah Total & $\mathbf{2 7 3 . 6 0 0 . 0 0 0}$ & $\mathbf{1 0 0}$ \\
\hline
\end{tabular}

Sumber : RKAS SDN 34/1 Teratai Tahun Anggaran 2017

Berdasarkan tabel diatas diketahui bahwa realisasi dana terbesar adalah pada pengembangan Perpustakaan yaitu sebesar Rp. 56.184.000.-. Untuk realisasi Kegiatan Penerimaan Peserta Didik Baru sebesar Rp. 6.527.150,-. Sedangkan untuk Kegiatan Pembelajaran dan Ekstrakurikuler sebesar Rp. 68.047.750.-. Realisasi untuk Kegiatan Evaluasi Pembelajaran sebesar Rp. 17.239.500.-. Pengelolaan Sekolah sebesar Rp. 27.200.000,-. Pengembangan Profesi Guru dan Tenaga Kependidikan serta Pengembangan Manajemen Sekolah sebesar Rp. 17.660.000.-, Langganan Daya dan Jasa sebesar Rp. 14.807.600.-, Pemeliharaan dan Perawatan Sapras Sekolah Rp. 27.439.000.-. Pembayaran Honor sebesar Rp. 32.995.000.-. Pembelian/ Perawatan Alat Multimedia Pembelajaran 5.500.000,-.

Meskipun jumlah dana Bos yang diterima SDN 34/1 Teratai cukup besar namun untuk realisasi penggunaan dalam meningkatkan kualitas dan kuantitas sekolah cukup baik, begitu pula dengan pengelolaannya. Pelaksanaan kegiatan pembelian barang dan jasa sesuai dengan prosedur melalui pertimbangan tim manajemen BOS. Pembelian barang/jasa memiliki mekanisme tersendiri yaitu dengan membeli barang yang paling dibutuhkan dengan segera oleh sekolah. Selain itu juga diterapkan prinsip efektif dan efisien. Efektif yang dimaksud ini adalah barang yang dibeli memang memiliki manfaat yang besar untuk kegiatan sekolah terutama untuk kebutuhan siswa. Prinsip kedua efisien, yaitu penggunaan dana terhadap pembelian barang tersebut dengan harga yang minimal, namun apabila dana yang tersedia masih cukup untuk mendapatkan barang/jasa dengan kualitas yang lebih baik dan harga yang tinggi maka akan dipertimbangkan untuk dilakukan pembelian.

Kewajiban perpajakan telah dilakukan oleh SDN 34/1 Teratai terkait transaksi-transaksi yang harus dilaksanakan pembayaran pajak pada penggunaan dana BOS. Penyetoran pajak dilaksanakan berdasarkan petunjuk teknis BOS dan Perundang-undangan yang berlaku. Pajak yang dikeluarkan adalah pajak pengeluaran penggunaan dana BOS dengan nominal mulai dari Rp. 1.000.000.- 
Analisis Pelaksanaan Dan Pengelolaan Dana Bantuan Operasional Sekolah (BOS) Pada Sekolah Dasar Negeri 34/1 Teratai

Penelitian ini membahas pelaksanaan pengelolaan dana BOS SDN 34/1 Teratai. Metode pengumpulan data yang telah dilakukan dalam penelitian ini adalah wawancara, observasi dan dokumentasi.

\section{Analisis Tahapan Pelaksanaan Dana BOS pada SDN 34 Teratai}

Tahapan pelaksanaan Dana BOS merupakan langkah- langkah yang harus dilakukan sebelum dan sesudah penerimaan Dana BOS dilakukan.

\section{Penyusunan RKAS}

SDN 34 Teratai menyusun Rencana Kegiatan dan Anggaran Sekolah (RKAS) sebelum menerima dan BOS diawal tahun berjalan. RKAS mencakup seluruh kegiatan sekolah yang akan dilaksanakan selama satu tahun.

\section{Pengambilan Dana}

Pengambilan dana BOS yang diterima SDN 34 Teratai dilakukan oleh kepala sekolah dan bendahara dana BOS.

\section{Penggunaan Dana}

SDN 34/1 Teratai merealisasikan dana BOS sesuai dengan RKAS yang telah disusun. Apabila dalam pelaksanaan kegiatan disekolah mengalami ketidaksesuaian dengan rencana yang telah dianggarkan di awal tahun pelajaran pada penyusunan RKAS maka SDN 34/1 Teratai mengalihkan alokasi dana tersebut kepada kegiatan lain yang tidak terduga sehingga dana tersebut tetap terealisasikan.

\section{Pembukuan}

Pembukuan dana BOS dilakukan oleh bendahara dana BOS. Pembukuan tersebut berisi jumlah dana yang dikeluarkan serta rincian pengeluaran. Pembukuan tersebut terdiri dari buku kas umum, buku pembantu kas,buku pembantu bank dan buku pembantu pajak.

Pembukuan dilakukan rutin setiap bulan oleh bendahara BOS dengan menyertakan bukti transaksi terhadap dana yang dikeluarkan berupa nota dan kwitansi bermaterai sesuai jumlah belanja. Bukti fisik tersebut berguna sebagai bukti fisik atas transaksi penggunaan dana BOS, sebagai pertanggung jawaban pengelola BOS sekolah terhadap pemerintah yang dilaporkan dalam bentuk SPJ setiap bulannya.

\section{Perpajakan}

Untuk kewajiban perpajakan SDN 34/1 Teratai telah melakukan pembayaran pajak melalui bank daerah yaitu bank 9 jambi terkait transaksi-transaksi yang telak dilaksanakan. Penyetoran pajak dilaksanakan berdasarkan petunjuk teknis BOS dan peraturan UndangUndang yang berlaku. Pajak yang dikeluarkan adalah pajak pengeluaran penggunaan dana BOS dengan nominal mulai dari Rp. 1.000.000.- dan lebih dari Rp. 1.000.000.- .

\section{Pelaporan}

Pelaporan pertanggung jawaban penggunaan dana BOS dilakukan sekolah dengan mengirimkan laporan kepada Dinas Kabupaten kota dalam bentuk SPJ pembelanjaan yang telah disusun sesuai ketentuan. Laporan dana BOS juga dilakukan secara online melalui website resmi kemdikbud. Selain mengirimkan laporan kepada dinas terkait sekolah juga mempublikasikan penggunaan dana BOS dengan cara menempelkan rincian penggunaan dana BOS di sebuah papan pengumuman khusus dana BOS, serta penyampaian langsung dalam rapat bersama wali murid,guru dan komite. Dengan begitu semua mengetahui kemana dana tersebut digunakan.

\section{Analisis Pengelolaan Dana BOS pada SDN 34/1 Teratai}

Dalam pengelolaan dana BOS di SDN 34/1 Teratai telah mengikuti ketentuan-ketentuan yang telah diatur didalam petunjuk teknis penggunaan dan pertanggungjawaban keuangan dana BOS yang diterbitkan oleh Direktorat Jendral 
Pendidikan Dasar dan Menengah Dinas Pendidikan dan Kebudayaan Republik Indonesia. Mulai dari segi perencanaan, pelaksanaan, pengawasan dan pelaporan telah dilakukan dengan baik oleh SDN 34/1 Teratai sesuai dengan ketentuan. Pelaporan dilakukan secara online melalui website resmi kemdikbud. Selain mengirimkan laporan kepada dinas terkait sekolah juga mempublikasikan penggunaan dana BOS dengan cara menempelkan rincian penggunaan dana BOS di sebuah papan pengumuman khusus dana BOS, serta penyampaian langsung dalam rapat bersama wali murid,guru dan komite.

Dalam kewajiban perpajakan sekolah telah melakukan kewajiban sebagaimana mestinya. Pada tahun 2017 terdapat temuan dari inspektorat terkait pajak dana BOS yang belum dibayarkan, namun hal itu bukan merupakan unsur kesengajaan melainkan karena kesalahanpemahaman terhadap sistematika pembukuan dan pelaporan..

Hasil analisis pengeloaan dana BOS yang ada di sekolah berdasarkan petunjuk teknis BOS tahun 2017 yang terdapat di SDN 34/1 Teratai yaitu sebagai berikut :

1. Sekolah membuat RKAS disusun dengan cara melakukan rapat antara tim manajemen dana BOS sekolah dengan seluruh majelis guru, dan juga komite sekolah dengan tujuan agar setiap anggaran diketahui oleh seluruh pihak yang ada diruang lingkup sekolah.

2. Sekolah menerima Dana BOS selama 4 Periode/ Triwulan, yaitu periode Januari-Maret, April-Juni, JuliSeptember, Oktober-Desember Dengan total dana Rp. 273.600.000,- dengan jumlah 342 siswa. Pada triwulan I Rp 52.190.000,- $\quad$ Triwulan II $\mathrm{Rp}$ 106.340.000,-, Triwulan III Rp 53.130.000,- dan triwulan IV Rp 61.940.000 jadi total seluruhnya Rp. 273.600.000,-

3. Pengambilan Dana BOS dilakukan oleh Kepala Sekolah dan Bendahara sekolah.
4. Sekolah telah melaksanakan penggunaan Dana BOS sesuai dengan petunjuk teknis BOS tahun 2017. Dana BOS tahun 2017 seluruhnya digunakan untuk sekolah mulai dari pembelian buku peganggan guru dan siswa hingga perawatan sekolah, pembuatan taman, dan kebutuhan sekolah lainnya yang sesuai dengan ketentuan.

5. Sekolah melakukan kegiatan pembelanjaan sesuai dengan petunjuk teknis BOS dengan tetap memperhatikan peraturan. Membuat laporan singkat tertulis tentang pengeluaran dana BOS dalam pelaksanaan pembelanjaan barang/jasa.

6. Sekolah membuat pembukuan terkait Pengelolaan Dana BOS terdiri dari buku kas umum, buku pembantu bank, dan buku pembantu pajak. Pelaksanaan pembukuan oleh Bendahara BOS setiap bulan sekali terkait transaksi Dana BOS. Transaksi yang dibukukan Bendahara BOS dilengkapi bukti transaksi.

7. Sekolah melakukan penyetoran PPN sebesar $10 \%$ untuk nilai pembelian lebih dari $\mathrm{Rp}$ 1.000.000,-atas pembelian buku pelajaran pengangan guru dan siswa dan pengadaan lain yang melebihi Rp. 1.000.000. PPH 21 untuk upah tukang dalam rangka rehabilitasi sekolah dipotong $5 \%$ apabila upah melebihi harian $\mathrm{Rp}$. 300.000. Penyetoran pajak terkait konsumsi rapat,transportasi KKG,pembelian bahan perawatan sekolah, dan lain-lain.

8. Pengawasan Dana BOS pada SDN 34/1 Teratai meliputi pengawasan melekat, fungsional dan pengawasan masyarakat . Hal itu, dilakukan oleh pihak internal maupun eksternal . Pihak internal sekolah yang melakukan pengawasan adalah komite sekolah dan dinas kabupaten bersama dengan pengawas sekolah. Sedangkan pihak eksternal yang melakukan pengawasan adalah dinas pendidikan provinsi dan 
pusat. Komite sekolah selaku pihak internal sekolah melakukan pengawasan atas terlaksanannya pengelolaan dana BOS melalui pemantauan pengelolaan BOS apakah sudah sudah sesuai dengan perencanaan. Monitoring yang dilakukan oleh Dinas Pendidikan Kabupaten yaitu pada saat periode berjalan pengelolaan dana BOS.

9. Dinas pendidikan dan inspektorat kabupaten terkait melakukan evaluasi terhadap LPJ atas pengelolaan dana BOS. Evaluasi diberikan jika ada kesalahan dalam tata cara pembukuan ataupun perincian penggunaan Dana BOS sehingga mengharuskan sekolah merevisi ataupun mengulang laporan. Pengelolaan dana BOS pada SDN 34/1 Teratai berjalan baik dan terbuka. Pada saat pemeriksaan oleh inspektorat hanya terdapat sedikit kekeliruan pada laporan yaitu tidak mencantumkan bukti pembayaran pajak.

10. Pada SDN 34/1 Teratai pelaporan dilakukan dengan mengirimkan laporan kepada Dinas Kabupaten kota dalam bentuk SPJ pembelanjaan yang telah disusun sesuai ketentuan dimana dilengkapi dengan bukti transaksi. Laporan disusun per triwulan sesuai penggunaan dana BOS. Laporan dana BOS juga dilakukan secara online melalui website resmi kemdikbud.

11. Sekolah mempublikasikan penggunaan dana BOS dengan cara menempelkan rincian penggunaan dana BOS di sebuah papan pengumuman khusus dana BOS, serta penyampaian langsung dalam rapat bersama wali murid,guru dan komite.

Berdasarkan penjelasan diatas diketahui bahwa pelaksanaan pengelolaan dana BOS SDN 34/1 Teratai sudah berjalan cukup baik sebagaimana mestinya sesuai dengan petunjuk Pertanggung jawaban penggunaan dana BOS tahun 2017 meskipun masih ada beberapa kesalahan, namun itu bukan merupakan unsur kesengajaan sehingga berakibat merugikan negara. Hal, itu hanya kesalahan pemahaman terhadap juknis BOS. Dimana, kesalahan yang sering terjadi hanya seputar pembukuan dan pelaporannya, terutama dalam bundel SPJ. Karena, didalam buku panduan ketentuan baku tentang bundel SPJ tidak dikatakan dengan jelas. Akibatnya ada perbedaan pengertian dalam penerjemahan kelengkapan SPJ yang dibutuhkan.

\section{SIMPULAN}

Berdasarkan hasil penelitian dan pembahasan seperti yang telah dijelaskan maka dapat disimpulkan sebagai berikut :

1. Pelaksanaan dana Bantuan Operasional Sekolah (BOS) pada Sekolah Dasar Negeri No. 34/1 Teratai tahun 2017 mengacu pada Peraturan Menteri Pendidikan Dan Kebudayaan No. 08 dan 26 Tahun 2017 Tentang Petunjuk Teknis Penggunaan Dan Pertanggungjawaban Keuangan Dana Bantuan Operasional Sekolah. Pelaksanaan telah berjalan efektif meskipun tidak seluruh rencana berjalan sesuai perencanaan dikarenakan ketidaksesuaian rencana yang telah disusun oleh sekolah. Sehingga sekolah harus membuat kegiatan perubahan untuk menggantikan kegiatan yang tidak terealisasi serta melakukan pengalihan dana pada kegiatan lain agar tidak terjadi penyelewengan.

2. Pengelolaan dana BOS SDN 34/1 Teratai sudah sesuai dengan kaidah pengelolaan dana BOS yang harus transparan dan terbuka. Dana digunakan sesuai dengan komponen pembiayaan yang telah ditetapkan didalam petunjuk teknis Penggunaan Dan Pertanggungjawaban Keuangan Dana Bantuan Operasional Sekolah. Tim manajemen BOS SDN 34/1 Teratai selalu memasang penggunaan dana BOS per triwulan di papan pengumuman dan melakukan pemberitahuan kepada komite dan wali murid saat rapat. Sekolah juga memasang spanduk bebas biaya/pungutan. 
3. Berdasarkan analisa yang dilaksanakan pelaksanaan pengelolaan dana BOS SDN 34/1 Teratai sudah berjalan sebagaimana mestinya sesuai dengan petunjuk Pertanggung jawaban penggunaan dana BOS tahun 2017 meskipun masih ada sedikit kesalahan, namun bukan merupakan unsur kesengajaan.

\section{DAFTAR PUSTAKA}

Eka Rezeki Amalia. 2008 . Pengelolaan Manajemen Keuangan Sekolah di SDN Mulyoagung dan MAN 1 malang. Tugas Akhir. Malang: Universitas Muhammadiyah Malang

Jayatri, Monika. 2012, Analisis Pengelolaan Dana Bantuan Operasinal Sekolah (BOS) di SMPN 11 dan SMPN 1 Purworejo. Skripsi. Depok: Universitas Indonesia

Mulyasa. E. 2002. Manajemen Berbasis Sekolah. Cetakan Kesatu. Bandung : PT. Remaja Rosdakarya

Peraturan Pemerintah Republik Indonesia Nomor 48 Tahun 2008 tentang Pendanaan Pendidikan. Direktorat Jenderal Pendidikan Dasar: Kementrian Pendidikan dan Kebudayaan

Petunjuk Teknis Bantuan Operasional Sekolah (BOS SD) Sekolah Dasar. (2017). Direktorat Pembinaan SD: Direktorat Jenderal Pendidikan Dasar dan Menengah Kementrian Pendidikan dan Kebudayaan

Sugiono. 2016. Metode penelitian Kuantitatif, Kualitatif dan Kombinasi (Mixed Methods). Cetakan Ketiga. Bandung : Alfabeta

Suwendra, Roni. 2014. Analisis Pengelolaan Dana Bantuan Operasional Sekolah di Sekolah Dasar Negeri 01 Tanjung Jati VII Kota Talago, Kecamatan Guguk, Kabupaten Lima Puluh Kota, Tahun 2014. Skripsi. Pekanbaru: Universitas Islam Negeri Sultan Syarif Kasim Riau http://rekhopascapol.blogspot.co.id/2012/0 4/program-bantuan-operasionalsekolah-bos.html

http://www.anggaran.depkeu.go.id/dja/athu mbs/apbn/PENDIDIKAN1.pdf

http://gurupengertian.co/pengertianadministrasi-secara-umum-besertamenurut para-ahli https://id.wikipedia.org/wiki/Administrasi 